categoria contratual distinta dos contratos de serviço, são os mesmos contratos, característica e um só regime mais protetivo regime para os consumidores.

Concorde-se, pois, com a análise de Atiyah, ${ }^{125}$ que desde 1980 há, pelo menos no direito dos contratos, um retorno aos princípios clássicos, justamente porque no mundo pós-moderno e liberal a autonomia de vontade é um dos instrumentos de eficácia econômica. Sempre é, porém, necessário "controlar" e "redistribuir", função esta hoje repassada ao direito do consumidor e da concorrência, em um mercado livre e atuante, como hoje o brasileiro. É na ousadia da reconstrução, em tempos de desconstrução, que pode estar a função da Teoria Geral. Realizamos neste - talvez longo demais - artigo uma análise tradicional, fortemente abstrata e generalizante, mas com resultados que parecem-me altamente positivos, de descoberta dos instrumentos e normas atualizante e necessárias presentes no CDC. A proposta desta reconstru ção é permitir cada vez mais uma melhor utilização prática deste ousado sistema.

Concluo, pois, que é possível propor uma teoria geral do fornecimento dos serviços com base no CDC. Este microssistema traz uma série de modificações e adaptações a seu espírito protetivo e privilegiador dos consumidores em geral, que deve ser leva-

125. ATIYAH, pp. 27 e ss.

126. Número 4 da ementa do acórdão TJRS, El 599178050, $9^{9}$ Grupo Cível, j. 17.08.1999, Des. Fernando Braf Henning Júnior.

127. Des. Elaine Harzheim Macedo do TJ/RS, voto, p. 20, in El 599178050, $9^{9}$ Grupo Civel, j. 17.08.1999, Rel. Des. Fernando Braf Henning Júnior.

Revista da Faculdade de Direito da UFRGS, v. 18, 2000 do em conta, em verdadeira evolução necessária do sistema de prestação de serviços do direito comum. O grande desafio do aplicador da lei é conhecer tão bem este sistema especial, de forma a utilizá-lo cada vez mais na prática. Aos advogados, defensores públicos, procurados e membros do Ministério Público está lançado o desafio. Parece-me que a jurisprudência brasileira já está pronta para tal visão nova dos "serviços de consumo". Assim, faço minhas as belas e ousadas palavras do TJ/RS em caso recente de consórcio:

“... a relação jurídica consortil reclama abordagem sob a égide das regras de consumo, em face da nova realidade denominada de 'pós-moderna', reflexiva da globalização e acumulação de riquezas e bens intangíveis, conquanto reservado ao princípio da boa-fé objetiva as funções de modificação, adaptação à prestação contratual, ou mesmo à resolução do coné só solidária, mas também objetiva. Se congo de Defesa do Consumidor, com os olhos do velho, ou seja, do Código Civil Brasileiro, vamos passar a ser merecedores da crítica que Pontes Miranda já fazia: 'O Brasil se especializou em fazer reformas que nada mudam'". ${ }^{127}$ No caso da teoria geral os serviços no CDC, a mudança já aconteceu... trato". ${ }^{126}$ "A responsabilidade, no caso, não tinuarmos a olhar o novo, ou seja, o Códi-

\title{
Códigos Únicos Y Restatements para Unificar La Regulación Internacional Del Contrato
}

\author{
(Su influencia en el Proyecto de Código Civil de 1998)
}

\section{Claudia R. Prirrio}

Profesora regular de Derecho Civil - Contratos de la Facultad de Derecho de la Universidad Nacional de Mar del Plata (República Argentina). Profesora honoraria de la Universidad Católica Santa María de Arequipa (Perú). Profesora visitante de la Facultad de Derecho de la Universidad de la República (Montevideo, Uruguay).

1.

Las circunstancias actuales. En la segunda mitad del siglo XX se asistió al fenómeno de creación de grandes bloques económicos, con formas políticas adecuadas a ellos.

Luego de la $2^{\text {a }}$ Guerra Mundial, en Europa se ensayaron mecanismos de integración. En 1948 Bélgica, Holanda y Luxemburgo formaron el Benelux. Luego, la Comunidad Europea del Carbón y el Acero resultó del Tratado de París del 18 de abril de 1951, y fue integrada por Alemania, Bélgica, Francia, Holanda, Italia y Luxemburgo.

Estos mismos países firmaron, el 25 de marzo de 1957, el Tratado de Roma, constitutivo de la Comunidad Económica Europea, con la finalidad de formar gradualmente un mercado común (artículos 3 y 8 del Tratado), creando -entre otros órganos- el Consejo de Ministros, la
Comisión, y la Corte de Justicia. Conforme al artículo 189 del Tratado de Roma (según el Tratado de Maastricht del 7 de febrero de 1992), "el Parlamento Europeo y el Consejo conjuntamente, el Consejo y la Comisión adoptarán reglamentos y directivas"; la directiva "obligará al Estado miembro destinatario en cuanto al resultado que debe conseguirse, dejando, sin embargo, a las autoridades nacionales la elección de la forma y de los medios". Las directivas tienden a "la aproximación de las legislaciones nacionales en la medida necesaria para el funcionamiento del mercado común" (artículo 3, inciso h). A su vez, hay una Corte de Justicia de la Comunidad, que garantiza "el respeto del Derecho en la interpretación y aplicación" del Tratado de Roma (artículo 164), y resguarda al Derecho Comunitario, al propender a su aplicación uniforme por los Estados miembros, y evitar que los Derechos 
locales contraríen sus principios (artículo 177); por lo demás, los Estados miembros están obligados a adoptar "todas las medidas generales o particulares apropiadas para asegurar el cumplimiento de las obligaciones" resultantes del Tratado (artículo 5) ${ }^{1}$.

En 1986 el número de miembros fue ampliado a 12 , y con posterioridad Alemania Oriental quedó incorporada conforme al principio de sucesión de Estados, al producirse la reunificación con Alemania Federal. El 31 de diciembre de 1992 se constituyó el mercado interior, concebido como "un espacio sin fronteras interiores, en el que la libre circulación de mercancías, personas, servicios y capitales estará garantizada"2. El Tratado de Maastricht dio vida a la Unión Europea, que desde 1995 está integrada por 15 países.

En Europa existe un Derecho Comunitario, con alcances de "orden jurídico propio", que "forma parte de los sistemas legales de los Estados miembros, y que sus tribunales están precisados a

1. Alterini, A. A., "La supremacía jurídica en el MERCOSUR", en L.L., t 1995-E, pág. 848.

2. Artículo 8-A del Tratado, añadido por el artículo 13 del Acta Unica Europea del 17 y el 28 de febrero de 1986.

3. Tribunal de Justicia de la Comunidad Económica Europea, sentencia del 15 de julio de 1964, "Costa v. EN EL".

4. Tribunal de Justicia de la Comunidad Económica Europea, sentencia del 5 de febrero de 1963, "Van Gend \& Loos"; sentencia del 9 de marzo de 1978, "Simmenthal".

5. Sobre esto Alterini, A. A. - Boldorini, M. C., El sistema jurídico en el MERCOSUR. Estructura general, Buenos Aires, 1994, pág. 56 y sigs.

6. Sentencia del 19 de noviembre de 1991, "Francovich y Bonifaci". La Directiva del Consejo 80/987, del 29 de octubre de 1980, dispuso que los Estados miembros adoptaran las medidas necesarias para que los derechos de los trabajadores asalariados fueran atendidos por instituciones de garantía en caso de insolvencia del empleador, pero Italia no organizó el sistema. Siguiendo su jurisprudencia tradicional que asigna responsabilidad a los Estados miembros cuando el Derecho local se aparta del Derecho comunitario (sentencia in re "Humblet", del 16 de diciembre de 1960) la Corte, en el caso, reiteró que tal responsabilidad "encuentra directamente su fundamento en el Derecho comunitario", y condenó a Italia a indemnizar a los trabajadores. Para ello, consideró que la Directiva 80/987 tenía aplicabilidad inmediata ante la falta de ejecución de sus disposiciones (ratificando así la doctrina de la sentencia in re "Becker", del 19 de enero de 1982); y que los sujetos del Derecho comunitario son no sólo los Estados sino también los particulares, quienes están legitimados para demandar cuando los derechos que de él emanan se incorporan directamente a su patrimonio jurídico. Ver Alterini, A. A., "La supremacia jurídica en el MERCOSUR", cit. (artículo 1). En diciembre de 1995 suscribieron un Acuerdo Marco Interregional de Cooperación con la Unión Europea, y en 1996 dos acuerdos de libre comercio con Chile ${ }^{7}$ con Bolivia.

El Acuerdo de Integración Subregional de Cartagena fue suscripto el 25 de mayo de 1969 por Bolivia, Colombia, Ecuador, Chile y Perú -con la ulterior incorporación de Venezuela-, teniendo como metas una Unión Aduanera, la Unión Andina, en el mediano plazo, y la Unión Económica en el largo plazo. Tras la cumbre presidencial efectuada en la ciudad de Trujillo en marzo de 1996 se dio paso a la Comunidad Andina de Integración (CAI) y al Sistema Andino de Integración (SÄI), nueva denominación del Acuerdo de Cartagena.

También existen la Asociación Latinoamericana de Integración (ALADI) fruto del Tratado de Montevideo del 12 de agosto de 1980, que reemplazó a la Asociación Latinoamericana de Libre Comercio (ALALC) creada en 1960; el Mercado Común Centroamericano (MCCA), resultante del Tratado de Managua de 1960, que integran Costa Rica, El Salvador, Guatemala, Honduras y Nicaragua; el Mercado Común Caribeño (CARICOM) que comprende a 15 países, creado por el Tratado de Chaguaramas de 1973; el Acuerdo de Libre Comercio del

7. Con la modalidad de acuerdo de asociación

8. Peña, F., "MERCOSUR y la inserción competitiva de sus países miembros en la economía internacional", en EI Mercado Común del Sur, Buenos Aires, 1992, pá́. 499.

9. Olivera, J. H. G., "El modelo constitucional de integración económica", en Anales】. \Academia Nacional de Derecho y Ciencias Sociales de Buenos Aires, $2^{\circledR}$ época, año XXXIII, № 26, pág. 329; Alterini, A. A., La inseguridad jurídica, Buenos Aires, 1993, pág. 60.
Grupo de los Tres (G3) del 13 junio de 1994 que vincula a México, Colombia y Venezuela; el Tratado de Libre Comercio de América del Norte (North American Free Trade Agreement, o NAFTA) que vincula a los Estados Unidos, México y Canadá desde el 1ㅇ de enero de 1994; el Área de Libre Comercio de las Américas (ALCA) que agrupa a 34 países y nació en la Cumbre de las Américas de Miami de 1994.

Esas organizaciones reflejan la "tendencia mundial a los mega-mercados". Desde el punto de vista jurídico conciernen a la eficiencia y a la seguridad, pues hacen posible algún modo de compatibilización de las legislaciones nacionales. El sistema legal es uno de los componentes del entorno de la actividad empresaria, cuyas variables es imposible conocer y controlar en su totalidad. Pero las incertidumbres propias de la actividad empresarial, esto es las que derivan del mercado y del cambio tecnológico, pueden ser acotadas en el terreno jurídico, evitando agregarles las incoherencias de los sistemas legislativos, que son una "tercera fuente de inseguridad, más peligrosa a veces que las otras" 9 . En eso está en compromiso la eficiencia, que es motor de la actividad empresarial moderna.

En la década de los años 90 irrumpió la globalización. Para tener noción de la magnitud con que se ha expandido cabe 
recordar que la Organización Mundial del Comercio (World Trade Organization), que reemplazó al GATT (General Agreement on Tariffs and Trade, o Acuerdo General sobre Aranceles Aduaneros y Comercio), agrupa a 135 países, siendo Estonia el último incorporado ${ }^{10}$. A su vez, la Convención de Viena sobre Compraventa Internacional de Mercaderías de 1980 ha sido ratificada por 56 países y rige en muchos países que estuvieron, o están, enrolados en el mundo comunista, por ejemplo, en China desde 1988 y en Cuba desde 1995.

2. Compatibilización de sistemas. Hoy parece haber sido abandonado el antiguo criterio según el cual el derecho -a diferencia de las demás ciencias- debería ser puramente nacional, e ignorante por lo tanto de cuanto sucede en otros países ${ }^{11}$. Subsiste a veces, sin embargo, un cierto amor propio que recela del reemplazo de las leyes nacionales por otras extranjeras ${ }^{12}$.

Un criterio para la compatibilización de varios sistemas es la armonización, mediante la cual se ponen en cierta sintonía las legislaciones de los diversos países.

Otro criterio es la unificación, que implica reemplazar las leyes nacionales por otras nuevas, comunes a varios países.

Hay distintos mecanismos para llevar a cabo esa compatibilización.
En algunos casos una misma norma es vinculante en una pluralidad de países:

a) Cuando varios países adoptan una legislación común mediante una convención internacional. Es el caso de la Convención de Viena sobre Compraventa Internacional de Mercaderías de 1980, a la que luego me referiré.

b) Un país puede adoptar la legislación de otro, como lo hicieron Holanda (en 1811), Haití (en 1825), Nápoles (en 1829), Bolivia (en 1830), Cerdeña (en 1830) y Santo Domingo (en 1844) con el Código Civil francés ${ }^{13}$, Cuba (en 1889) con el Código Civil español, o Paraguay (en 1889) con el Código Civil argentino.

c) En la Unión Europea, las directivas -como vimos- obligan a los países miembros a adecuar a ellas su legislación interna, no obstante que suelen dejarle cierto margen para adoptar criterios particulares ${ }^{14}$.

En el área del denominado Soft Law los instrumentos no tienen carácter normativo, pero constituyen un modelo ofrecido, sea a los países, sea a los particulares. Tal sucede en estas situaciones:

d) En las leyes modelo, que los países pueden adoptar, como en el caso de la Ley

10. Su incorporación como miembro de esa Organización fue aprobada por el Consejo General el 21 de mayo de 1999.

11. David, R., Traité élémentaire de droit civil comparé: Introduction a l'étude des droits étrangers et à la méthode comparative, Paris, 1950; Borba Casella, P., "Economic Integration and Legal Harmonization, with Special Reference to Brazil", en Uniform Law Review. Revue de Droit Uniforme, Roma, vol. III, 1998-2/3, pág. 287, № 4.

12. Gutteridge, H. C., Comparative Law, $2^{\text {nd }}$ ed., Cambridge, 1949, pág. 158.

13. También puede ser impuesto, como sucedió en Bélgica en 1804 con el mismo Código Civil francés.

14. Por ejemplo, la Directiva $85 / 374$ CEE del 15 de julio de 1985 sobre responsabilidad por el hecho de productos defectuosos autoriza a los Estados a incluir los productos agrícolas y de caza, que están excluidos de ella, y a involucrar al riesgo de desarrollo (artículo 15).

Revista da Faculdade de Direito da UFRGS, v. 18, 2000

Modelo sobre Comercio Electrónico de 1996 de la Comisión de las Naciones Unidas para el Desarrollo Mercantil Internacional o CNUDMI (UNCITRAL en el anagrama inglés de United Nations Commission on International Trade Law) ${ }^{15}$.

En países de organización federal como los Estados Unidos de América puede haber códigos modelo, tal es el caso del Uniform Commercial Code.

e) En los instrumentos preparados por organizaciones internacionales para ser incorporados en los contratos de lo particulares, como los Principios sobre los Contratos Internacionales de UNIDROIT. En su caso, también pueden ser tomàdos en cuenta por los tribunales como fundamento de sus sentencias ${ }^{16}$.

f) En los instrumentos preparados por organizaciones internacionales a fin de servir como guía para armonizar las prácticas contractuales, por ejemplo, la Guía Jurídica de la CNUDMI para la Redacción de Contratos Internacionales de Construcción de Instalaciones Industriales (1988). g) Otra vía es la de los restatements. Estos implican un replanteo del sistema, buscando criterios aplicables en distintas áreas del Derecho, tal es el caso, en los Estados Unidos de América, del Restatement of Contracts $2^{\text {nd }}$. Los restatements no se limitan a acopiar una pluralidad de soluciones alternativas para situaciones jurídicas idénticas, sino que arbitran entre ellas y eligen una u otra. Esta elección resulta valiosa cuando no se aparta demasiado de la solución prevaleciente, y se atiene a alguna regla generalmente familiar a los operadores de los distintos sistemas ${ }^{17}$.

Los restatements, según los casos, sirven a varios propósitos: permiten a las partes identificar problemas a ser resueltos en sus contratos, orientan a los tribunales ${ }^{18}$, llenan vacíos de la ley, suministran una base para su reforma, cumplen una función didáctica al delinear el jus commune y, en todo caso, aspiran a ser aplicados "no ratione imperii, sino imperio rationis" 19.

3. Textos básicos para la armonización legislativa en materia de

15. El 30 de junio de 1999 el gobierno de Australia envió al Parlamento un proyecto de Electronic Transactions Act, que se basa en la citada Ley Modelo de UNCITRAL. Ver http//Iaw.gov.au/ecommerce/.

16. La Convención Interamericana de México de 1994 sobre la Ley aplicable a los Contratos Internacionales admite que el tribunal tome en cuenta, a falta de elección del derecho aplicable, los principios del derecho comercial internacional reconocidos por organizaciones internacionales (artículo 9, inciso $2^{2}$ ). Las XVI Jornadas Nacionales de Derecho Civil (Buenos Aires, 1997) consideraron que "en los contratos internacionales resultan aplicables, como criterios de interpretación, los Principios de UNIDROIT sobre contratación internacional".

17. Goode, R., "International Restatement of Contract and English Contract Law", en Uniform Law Review. Revue de Droit Uniforme, Roma, vol. II, año 1997-2, pág. 234

18. En Holanda, durante el proceso de reformas del Código Civil, la Corte Suprema hizo una "interpretación anticipatoria" de los textos del viejo Código, sobre la base de los borradores de la reforma: Hartkamp, A., "Principles of Contract Law", en Hartkamp, A. - Hesselink, M. - Hondius, E. - Joustra, C. - du Perron, E. (Editors), Towards a European Civil Code, The Hague/London/Boston, 1998, pág. 105, ap. 3, nota 13.

19. Hartkamp, obra citada, ap. 3. 
contratos. El tema de la armonización legislativa del derecho privado en Europa genera tal interés que ha dado lugar a la aparición de revistas jurídicas especializadas en ella: en Alemania la Zeitschrift fur Europaisches Privatrecht, en Holanda la European Review of Private Law, en Italia la revista Europa e Diritto Privato. En materia contractual, el yacimiento de antecedentes modernos para encarar algún modo de armonización legislativa es vasto ${ }^{20}$. En mi opinión, son especialmente relevantes el Contract Code, el Anteproyecto de Código Europeo de Contratos, la Convención de Viena sobre Compraventa Internacional de Mercaderías de 1980, los Principios de UNIDROIT sobre Contratos Internacionales y los Principios del Derecho Europeo de Contratos. Los tres primeros tienen la impronta del efecto vinculante, y los dos últimos pertenecen a la categoría de los restatements.

El panorama se completa con las pertinentes Directivas de la Unión Europea, así como con el Uniform Commercial Code $y$ el Restatement of Contracts $2^{\text {nd }}$ de los Estados Unidos de América.

a) La Law Commission británica encargó en 1966 a Harvey McGregor -profesor en Oxford y en Londres, y Head

of Legal Chambers en Londres- la preparación de un proyecto de Código de Contratos, tarea en la que también tuvo intervención la Scottish Law Commision, y que concluyó en $1972^{21}$.

En el Prefacio del profesor Giuseppe Gandolfi a la edición española se lee que "las leyes inglesas se han venido diversificando constantemente de las del continente europeo, reflejando tanto estructuralmente como funcionalmente el tradicional carácter casuístico de aquel Derecho, en el que el juez está habituado a operar no sobre la base de enunciaciones abstractas, sino con referencia a los precedentes judiciales y recurriendo a la técnica de la 'distinción"'; pero el Proyecto McGregor, "aproximando las dos orillas del Canal de la Mancha, nos anuncia que, en el tercer milenio de nuestra era, nuestra cultura jurídica será el resultado de una colaboración entre estos dos mundos, hasta ahora distantes y contrapuestos". E Contract Code -con palabras de Jean Carbonnier ${ }^{22}$ - permite "regocijarse, porque por fin se ha realizado un Eurotúnel jurídico".

b) El Anteproyecto de Código Europeo de Contratos ${ }^{23}$ fue elaborado por la Academia de Jusprivatistas Europeos. El

20. Guido Alpa ("The accordance and Unification of Contract Law", en Italian National Reports to the XV' International Congress of Comparative Law, Bristol, 1998, pág. 364) señala que la cuestión ha sido examinada profundamente por los mejores juristas, y destaca que actualmente los estudios sobre Law and Economics también "han introducido instrumentos conceptuales uniformes para la evaluación de los efectos económicos de las reglas legales".

21. Contract Code: drawn up on behalf of the English Law Commission, Milano, 1994; Contract Code. Proyecto redactado por encargo de la Law Commision inglesa, trad. de la Cuesta Sáenz, J. M. y Vattier Fuenzalida, C., Barcelona, 1996.

22. En su intervención en el Coloquio de Pavía del 7 de octubre de 1995.

23. Ver Brizzio, C. R., "Anteproyecto de Código Europeo de Contratos. Estudio preliminar", en L. L., ej. 02.05.99; "Teoría general de contrato y contratos predispuestos en el Anteproyecto de Código Europeo de Contratos y en el Proyecto de Código Civil argentino de 1998 , en D.J., ej. del 07.04.99 y del 14.04.99.

Revista da Faculdade de Direito da UFRGS, v. 18, 2000
20 y el 21 de octubre de 1990 realizó en Pavía (Italia) el primero de una serie de Coloquios, del cual resultó la formación de un Grupo de Trabajo, coordinado por el profesor Giuseppe Gandolfi e integrado por alrededor de setenta juristas de todos los países europeos, entre los cuales están los presidentes de las respectivas cortes supremas. En las Notas Introductorias son mencionados expresamente -entre otroslos aportes de estos profesores: Antúnes Varela, de los Mozos, García Cantero, Bianca, Ferri, Cian, Giorgianni, Oppo, Rescigno, Carbonnier, Ghestin, Tunc, McGregor, Nicholas, Blaurock, Medicus, Posch, Schlechtriem, Sonnenberg, Stranard, Sturm, Wieacker, Sortais, Vigneron, Daskarolis, Jolowicz. Allí mismo se señala la incidencia que tuvieron las soluciones del Contract Code, de los Principles de la Comisión Landö (en su versión de 1995), de los Principios de UNIDROIT y de la Convención de Viena sobre Compraventa Internacional de Mercaderías de 1980. La primera parte del Anteproyecto fue dada a conocer el $30 \mathrm{de}$ octubre de 1995, y la segunda, el 24 de marzo de 1997.

En el Preámbulo se formula una serie de consideraciones interesantes para comprender su sentido. En un primer momento, el Grupo de Trabajo decidió tomar como "esquema de base" al Libro IV del Código Civil italiano de 1942, "en razón

24a doctrina especializada europea lo ha acogido con expectativa: Gandolfi, G., "Pour un Code européen des contrats", en Revue Internationelle de Droit Civil, 1992, pág. 707; Stein, P., Incontro di Studio su il futuro Codice europeo dei contratti, Milano, 1993; Mengoni, L., "L'Europa dei codici o un Codice per l' Europa", en Cuaderni del Centro di Studi e Ricerche di Diritto comparato e straniero, №7, Roma, 1993, pág. 14; Sacco, R., "The System of European Private Law: Premises for a European Code", en Italian Studies in Law, vol. I, Roma, 1993, pág. 71; de los Mozos, J. L., "Integración europea. Derecho Comunitario y Derecho común", en Revista de Derecho Privado, Madrid, año 1993, pág. 211. de su postura intermedia entre los dos principales filones jurídicos del continente (francés y alemán), y también porque, teniendo en cuenta la época en la cual fue redactado y la unificación que ha efectuado entre el Derecho civil y el Derecho comercial, está más próximo al Derecho inglés que los Códigos de las áreas antes mencionadas"; pero la ulterior presentación del Contract Code de McGregor "incitó al Grupo de trabajo a optar por un doble esquema de base constituido, por una parte, por el Contract Code y, por la otra, por el Libro IV del Código Civil italiano".

En dicho Preámbulo también se expresan los propósitos de "llegar a la redacción de un Código nuevo", comprensivo de "reglas destinadas a resolver los problemas, y no un compendio de principios", y de mantener "la unificación entre Derecho Civil y Derecho Comercial, que ha sido realizada por el Código italiano, ha sido seguida en otros países del continente, y está presente en substancia en la experiencia del Common Law" ${ }^{24}$.

c) La CNUDMI (o UNCITRAL) elaboró la Convención sobre Compraventa nternacional de Mercaderías, que fue aprobada en Viena el 11 de abril de 1980. a preparación de una ley uniforme a tal efecto comenzó en 1930 en UNIDROIT y, después de una larga interrupción debida a la Segunda Guerra Mundial, el correspondiente borrador fue sometido a la 
Conferencia de La Haya de 1964, que adoptó dos convenciones, una sobre la compraventa internacional de mercaderías, y otra sobre la formación del respectivo contrato. La Convención de Viena entró en vigor el 1 de enero de 1988, rigiendo originalmente en 11 Estados que presentan grandes diversidades geográficas, en los niveles de desarrollo económico, y en los sistemas legales y sociales: Argentina, China, Egipto, Francia, Hungría, Italia, Lesotho, Siria, Estados Unidos de América, Yugoslavia y Zambia. Argentina la ratificó en 1983 mediante la ley 22.765 y, por lo tanto, integra su Derecho: "Si el abogado argentino cree haber ganado las negociaciones sobre el derecho aplicable con el abogado de la parte contraria, por haber insertado una cláusula donde dice que 'el Derecho argentino será aplicable', grande será su sorpresa cuando descubra que el Derecho argentino aplicable es precisamente la Convención de Viena y no las normas sobre compraventa incorporadas al Código Civil y al Código de Comercio argentino que conocía desde su paso por la Facultad de Derecho"25. Igual sorpresa tendría el abogado de cualquiera de los países en los cuales la Convención es vinculante.

d) UNIDROIT (Instituto Internacional para la Unificación del Derecho Privado) dio a conocer en Roma, en 1994, los Principios sobre los Contratos Comerciales Internacionales ${ }^{26}$, con sus

correspondientes comentarios ilustraciones. Los Principios son el producto de un Grupo de trabajo especial, compuesto por profesores, magistrados y funcionario de alto rango, expertos en el Derecho de los contratos y en el Derecho del comercio internacional, que representaron a todos los principales sistemas jurídicos del mundo. En su Introducción se lee que "el objetivo de los Principios de UNIDROIT es establecer un conjunto equilibrado de reglas destinadas a ser utilizadas en todo el mundo, independientemente de las específicas condiciones económicas y políticas de los países en que vengan aplicados"; y en su Preámbulo, que los Principios "establecen reglas generales aplicables a los contratos mercantiles internacionales", que pueden aplicarse como "principios generales del Derecho" o como "Lex Mercatoria", y que "pueden servir de modelo para la legislación a nivel nacional o internacional". En el Comentario 3 se expresa que "a pesar de que los Principios han sido concebidos para los contratos mercantiles internacionales, no existe ningún impedimento para que los particulares puedan aplicarlos a contratos estrictamente internos o nacionales".

Los Principios UNIDROIT son "reglas, máximas de orden lógico y ético que implican, además de una decantación de la experiencia, una regla de conducta. Son útiles al legislador para redactar las normas que reglan la autonomía privada y al juez para calificar la conducta de las partes a lo

25. Garro, A. M. y Zuppi, A. L., La Convención de las Naciones Unidas sobre los Contratos de Compraventa Internacional de Mercaderias, en http://www.cisg.law.pace.edu/cisg/text/garro-zuppi.html. Idéntica situación se plantea en todos los países que han ratificado la Convención

26. Principios sobre los contratos comerciales internacionales, trad. A. M. Garro, Roma, 1995. largo de sus negociaciones, para calificar el acuerdo y resolver los conflictos que de él resultan, con pertinencia, lógica y ética. Sin contar el provecho que representa para el comercio la identificación de ciertas reglas comunes a la mayor parte de los órdenes jurídicos en cuya aplicación y respeto es posible confiar"27.

Los Principios ya han servido como fuente de inspiración de varios cuerpos de leyes: para los Códigos de Holanda (1992), de Québec (1992) y de la Federación Rusa (1994); para los proyectos de Códigos de Lituania, Checoslovaquia y Túnez; para las tareas de revisión del Uniform Commercial Code, del derecho de obligaciones en Alemania y en Estonia, y del derecho de contratos en la República China y en los 15 países miembros de la Organisation pour l'Harmonisation en Afrique du Droit des Affaires; como veremos, para el Proyecto de Código Civil argentino de $1998^{28}$.

e) El 26 de mayo de 1989 el Parlamento Europeo encargó la redacción de un Código Europeo de Derecho Común de Contratos (Common European Code of Private Law) a la Commision on European Contract Law presidida por el profesor de Copenhague Ole Landö (del Legal Department, Handelshøjskolen $i$ Københaun $[D K])$, y señaló como modelo al Proyecto franco-italiano de las obligaciones de 1927 , que influyó notoriamente en la redacción

27. Hinestrosa, F., "Des principes généraux du droit aux principes généraux des contrats", en Uniform Law Review. Revue de Droit Uniforme, Roma, vol. III, 1998-2/3, pág. 501, ap IX

28. Bonell, M. J., An International Restatement of Contracts. The UNIDROIT Principles of Internacional Commercial Contracts, $2^{\mathrm{a}} \mathrm{ed}$. New York, 1997, pág. 235.

29. Landö, O., "Homo judicans", en Uniform Law Review. Revue de Droit Uniforme, Roma, vol. III, 1998-2/3, pág. 535, ap. IV. Reflexoinando sobre los Principios, Legrand, P., "Sens et non sens d'un Code Civil Européen", en Revue Intermationale de Droil 
armonización resultaría especialmente viable mediante el mecanismo de instrumentos no vinculantes como los referidos Principios ${ }^{30}$.

f) El derecho de contratos es área propia de las Directivas de la Unión Europea. Entre ellas se destaca la Directiva del Consejo de la Comunidad Europea CEE 93/13 del 5 de abril de 1993, que descalifica las cláusulas abusivas en los contratos celebrados con los consumidores ${ }^{31}$

g) En el sistema norteamericano, el Uniform Commercial Code fue preparado por el American Law Institute y por la National Conference of Commissioners of Uniform State Laws, y trata principalmente de la compraventa de mercaderías -incluso cuando una parte no es comerciante-, con extensos comentarios oficiales. En la década de los años 60 comenzó a ser adoptado por los Estados de la Unión, y está sometido a permanente revisión y actualización.

El Restatement of Contracts $2^{\text {nd }}$ es uno de los Restatement of the Law del American Law Institute, organización académica que agrupa a alrededor de 300 miembros. La primera edición fue publicada en 1932 Sistematiza la jurisprudencia dominante,

trae comentarios y ejemplos ilustrativos, y su texto está en permanente actualización, pues "en alrededor de una generación las decisiones usualmente sobrepasan aún las más visionarias disposiciones del Restatement, y entonces se requiere una revisión"32.

4. La experiencia argentina. Argentina pertenece al MERCOSUR. En ella rigen el Código Civil desde 1871 y el Código de Comercio desde 1890. Paraguay dictó el Código Civil unificado con el de Comercio de 1987, fuertemente influido por el Código Civil italiano de 1942. Uruguay mantiene su Código Civil de 1893, modificado en 1914, y su Código de Comercio de 1866. Brasil, regido por el Código Civil de 1916, tiene su reforma en trámite legislativo desde 1975, recién en 1997 la sancionó la Cámara de Diputados y hoy, 25 años después, está en revisión en el Senado, que se encuentra con un proyecto que responde a ideas pretéritas que han sido abandonadas a fines del siglo.

En una arteria principal del mundo de los contratos modernos, el de los contratos de consumo, Brasil dictó su Código de Defensa del Consumidor en

Comparé, año XLI, № 4, octubre-diciembre de 1996, pág. 779, entiende en cambio que, antes bien que mediante un Código unificado, entre los sistemas del derecho continental europeo y del Common Law debe haber un intercambio de ida y vuelta, sin que uno de ellos absorba al otro.

30. Bonell, M. J., "Verso un Codice europeo di contratti??, en Europa e Diritto Privato, Roma, № 1998-1, pág. 171, ap. 5 y 6.

31. Ha sido incorporada a los Derechos nacionales del Reino Unido (Unfair Terms in Consumer Contracts Regulations, 1994), de Irlanda (Unfair Terms in Consumer Contracts Regulations, 1995), de Portugal (decreto ley 220/95), de Italia (ley 52-1996) y de España (ley 7-1998). La legislación anterior a la Directiva (Ley alemana sobre condiciones generales de contratación de 1977; ley francesa 78/23 del 10 de enero de 1978; Konsumentenschutzgesetz [KSchG] 140/1979 austríaca; ley belga del 14 de julio de 1991; Código Civil holandés de 1992, $L^{\circ} 6$, artículo 231 y siguientes) no precisa ser modificada en la medida en que se adecua a ella, como lo ha resuelto la Corte de Justicia de la Comunidad Europea (caso 29/84, "Comisión c/Alemania", 29 de mayo de 1985).

32. Hyland, R., "The American Restatements and the Uniform Commercial Code", en Hartkamp, A. - Hesselink, M. - Hondius, E. Joustra, C. - du Perron, E. (Editors), Towards a European Civil Code, cit., pág. 55, ap. 2.

Revista da Faculdade de Direito da UFRGS, v. 18, 2000
1990, Argentina su Ley de Defensa del Consumidor en 1993, pero Paraguay recién la sancionó en 1998, y en el segundo semestre del año 2000 entrará en vigencia en Uruguay. No hay mucho de común en esas legislaciones estatutarias, tanto que el Proyecto de Protocolo de Defensa del Consumidor, elaborado por la Comisión Técnica № 7 del MERCOSUR en noviembre de 1997, fracasó porque Brasil consideró que cerca de 40 de sus disposiciones implicaban retrocesos respecto de las soluciones de su Código de Defensa del Consumidor.

En el MERCOSUR, no obstante el gigantismo de su territorio, que exige soluciones comunes para el transporte a fin de evitar distorsiones e incertidumbres en las operaciones transfronterizas, el Acuerdo de Transporte Multimodal Internacional, proveniente de la Decisión del Consejo del Mercado Común № 15/94, no termina de ser ratificado por los Estados Partes, y en Uruguay está puesto en jaque por pretensiones de inconstitucionalidad.

Brasil tampoco ratificó los Tratados de Derecho Internacional Privado de Montevideo, pues en la solución del conflicto de leyes prefiere orientarse por los criterios del Código de Bustamente.

De esas evidencias resulta claro que el mandato del Tratado de Asunción de

33. El Proyecto fue presentado al Ministerio de Justicia el 18 de diciembre de 1998, con la firma de los profesores doctores Héctor Alegría, Atilio Aníbal Alterini, Jorge Horacio Alterini, María Josefa Méndez Costa, Julio César Rivera y Horacio Roitman El 8 de julio de 1999 el Poder Ejecutivo lo remitió a la Cámara de Diputados de la Nación con el Mensaje № 731.

34. La Convención de Viena de 1980, que representa la ideología del derecho nuevo en materia contractual, ya había orientado las soluciones del Proyecto argentino de Código Único de 1987.

35. Entre ellos el boliviano de 1975, el peruano de 1984, el paraguayo de 1987, el holandés de 1992, el quebequés de 1992, el de la Federación rusa de 1994, el mongol de 1994 y el vietnamita de 1995. armonizar las legislaciones en el MERCOSUR no está a la vista en el horizonte próximo. Ni siquiera rige en todos los países que lo integran la Convención de iena sobre Compraventas Internacionale de Mercaderías de 1980. Esta Convención se aplica en Argentina desde el $1 \stackrel{0}{\circ}$ de enero de 1988, y en Uruguay se aplicará desde el $1^{\circ}$ de febrero del año 2000 , pero no la han ratificado ni Brasil ni Paraguay.

Con ese panorama, en Argentina tiene estado legislativo el Proyecto de Código Civil unificado con el de Comercio de $1998^{33}$, que no ha podido intentar armonización alguna con el derecho de los otros países del MERCOSUR, por lo cual, en la regulación de la teoría general del contrato, hace una propuesta apta para generar adhesiones en la región. Según surge de la Nota de elevación y de los Fundamentos del Proyecto, para su redacción se han tomado en cuenta todos los antecedentes que hemos venido analizando ${ }^{34}$, así como los Códigos Civiles dictados en los últimos años ${ }^{35}$

Propongo hacer un test con uno de los aspectos principales de dicha teoría general del contrato, el de su formación.

Sobre los requisitos de la oferta, el artículo 1148 del Código Civil argentino dispone que debe ser hecha "a persona o personas determinadas sobre un contrato 
especial, con todos los antecedentes constitutivos de los contratos". En cuanto a la exigencia de que el destinatario de la oferta sea determinado, la nota al artículo invoca el criterio de Savigny ${ }^{36}$, aunque su fuente directa es el artículo 1852, inciso 2 del Esboço de Freitas. Los requisitos relativos al contrato especial y a sus antecedentes constitutivos también resultan del inciso 39 del mismo artículo del Esboço.

Sobre los términos de la aceptación, el artículo 1152 del Código Civil argentino establece que "cualquiera modificación que se hiciere en la oferta al aceptarla, importará la propuesta de un nuevo contrato". Este texto proviene del artículo 1847 del Esboço.

Sobre la caducidad de la oferta también tomando el modelo de Freitas (artículo 1844) - el artículo 1149 del Código Civil argentino dispone que "la oferta quedará sin efecto alguno si una de las partes falleciere, o perdiere su capacidad para contratar: el proponente, antes de haber sabido la aceptación; y la otra, antes de haber aceptado". La nota correspondiente invoca la opinión de Pothier ${ }^{37}$, quien se plantea este caso: envío a un comerciante una oferta de compra de mercaderías a cierto precio, y antes de que la carta le haya llegado muero o pierdo la razón; en tal situación no ha habido contrato de venta, pues "no habiendo perdurado mi voluntad hasta el momento

en que ese comerciante ha recibido la carta y aceptado la propuesta que ella contenía, no ha coincidido un consentimiento o concurso de nuestras voluntades necesario para formar el contrato de venta".

La regulación de esos aspectos de la teoría general del contrato ha sufrido profundas modificaciones en el derecho moderno, resultantes - entre otros-del Código Civil alemán, del Código Suizo de las Obligaciones, del Proyecto francoitaliano de 1927, de la Convención de La Haya relativa a un Derecho Uniforme en la Formación de los Contratos de Compraventa Internacional de Mercaderías de $1964^{38}$ y, más recientemente, de la Convención de Viena sobre Compraventa Internacional de Mercaderías de 1980. Tales modificaciones han sido recogidas en los proyectos de unificación internacional del derecho de los contratos que he mencionado con anterioridad.

a) Oferta al público. En cuanto al destinatario de la oferta, en la actualidad se acepta la fuerza vinculante de la oferta al público. Es el criterio de la Convención de La Haya relativa a un Derecho Uniforme en la Formación de los Contratos de Compraventa Internacional de Mercaderías de 1964 (artículo 4.1), de la Convención de Viena sobre Compraventa Internacional de Mercaderías de 1980 (artículo 14.1), del Contract Code (artículo 15), del

36. En la nota a ese artículo se señala la opinión contraria de Zachariae, para quien "no es necesaria la determinación de la persona". La misma solución del artículo 1149 del Código Civil resulta del artículo 454 del Código de Comercio.

37 "Traité du contrat de vente", № 32, en Oeuvres de Pothier, t², Paris, 1855, pág. 14.

38. Esta Convención, preparada por UNIDROIT, fue ratificada por el Reino Unido, San Marino, Bélgica, Holanda, Italia, Alemania Federal, Luxemburgo e Israel, pero -luego de haber sido celebrada la Convención de Viena sobre Compraventa Internacional de Mercaderías de 1980- la mayoría de estos países la denuncí.

Revista da Faculdade de Direito da UFRGS, v. 18, 2000
Anteproyecto de Código Europeo de Contratos (artículo 13 , inciso $2^{\circ}$ ) y de los Principios del Derecho Europeo de Contratos (artículo 2.201 [2])

Coincidentemente, el artículo 922 del Proyecto de Código Civil argentino de 1998 admite que la oferta sea dirigida "a persona determinada o determinable" (inciso b).

b) Intención de quedar obligado. En cuanto a los demás requisitos de la oferta, ya no se requiere que la oferta contenga todos los elementos constitutivos del contrato que se propone, bastando con que sea suficientemente precisa e indique la intención del oferente de quedar obligado en caso de ser aceptada. Es el criterio de la Convención de La Haya relativa a un Derecho Uniforme en la Formación de los Contratos de Compraventa Internacional de Mercaderías de 1964 (artículo 4.1), de la Convención de Viena sobre Compraventa Internacional de Mercaderías de 1980 (artículo 14.1), de los Principios sobre los Contratos Comerciales Internacionales de UNIDROIT (artículo 2.2), del Contract Code (artículo 15), del Anteproyecto de Código Europeo de Contratos (artículo 13, inciso $1^{\circ}$ ) y de los Principios del Derecho Europeo de Contratos (artículo 2.201 [1]).

En el mismo sentido, el artículo 922 del Proyecto de Código Civil argentino de 1998 prevé que "Para que haya oferta la manifestación del oferente debe: a) Indicar, de acuerdo con los usos y las circunstancias

9. Modificando el criterio del artículo 1322 del Código Civil de 1936

40. El artículo 681 del Código Civil paraguayo de 1987, sin embargo, se atiene al criterio antiguo. del caso, su intención de contratar [...]. c) Contener las precisiones necesarias para establecer los efectos que producirá el contrato si la oferta llega a ser aceptada".

c) Aceptación con modificaciones. El criterio actual es que las modificaciones no sustanciales que el aceptante introduzca a la oferta no significan su rechazo, por lo cual se le asigna al oferente el derecho a admitirlas, siempre que lo comunique de inmediato al aceptante. Tal resulta de la Convención de La Haya relativa a un Derecho Uniforme en la Formación de los Contratos de Compraventa Internacional de Mercaderías de 1964 (artículo 7.2), de la Convención de Viena sobre Compraventa Internacional de Mercaderías de 1980 (artículo 19.2), de los Principios sobre los Contratos Comerciales Internacionales de UNIDROIT (artículo 2.11 [2]), del Anteproyecto de Código Europeo de Contratos (artículo 16, inciso 7), de los Principios del Derecho Europeo de Contratos (artículo 2.208, incisos 2 y 3 [b]), del Código Civil peruano de 1984 (artículo 1376 39 ). ${ }^{40}$

En esa moderna línea de ideas, el artículo 929 del Proyecto argentino de Código Civil de 1998 establece que "para que haya aceptación expresa el aceptante debe realizar una manifestación que: a) Dé conformidad con la oferta. Las modificaciones sustanciales que el aceptante introduce a la oferta importan su rechazo, pero las otras modificaciones pueden ser admitidas por el oferente si lo comunica de inmediato al aceptante". 
d) Aceptación tardía. Conforme al Código Suizo de las Obligaciones el oferente tiene derecho a admitir que una aceptación tardía "ha sido recibida en tiempo" (artículo 5 , inciso $2^{\circ}$ ). El mismo criterio fue seguido por el Proyecto franco-italiano de 1927 (artículo 2), por el Código Civil italiano de 1942 (artículo 1326), por el Código Civil venezolano (artículo 1137), por la Convención de La Haya relativa a un Derecho Uniforme en la Formación de los Contratos de Compraventa Internacional de Mercaderías de 1964 (artículo 9.1), por la Convención de Viena sobre Compraventa Internacional de Mercaderías de 1980 (artículo 21.1), por el Código Civil peruano de 1984 (artículo 137641). Son coincidentes las soluciones de los Principios sobre los Contratos Comerciales Internacionales de UNIDROIT (artículo 2.9 [1]), del Contract Code (artículo 25, inciso $1^{\circ}$ ), del Anteproyecto de Código Europeo de Contratos (artículo 16, inciso 5) y de los Principios del Derecho Europeo de Contratos (artículo 2.207 [1]) ${ }^{42}$.

El Proyecto argentino de Código Civil de 1998 enrola en esa idea. Su ya citado artículo 929 dispone que "Para que haya aceptación expresa el aceptante debe realizar una manifestación que [..] b) Sea emitida dentro del tiempo de vigencia de la oferta. Pero el oferente puede prevalerse de una aceptación tardía si lo comunica de inmediato al aceptante".

Esta flexibilización del iter formativo del contrato ha recibido el apoyo de las I Jornadas del Fin del Mundo de Derecho Privado (Ushuaia, 1996) ${ }^{43}$.

e) Caducidad de la oferta. Con respecto a la caducidad de la oferta, el Código Civil alemán privó de relevancia a "la circunstancia de que el oferente muera o se haga incapaz de celebrar negocios jurídicos antes de la aceptación" (§ 153). Es la solución adecuada a las exigencias de seguridad del tráfico negocial moderno, en el cual interesa la declaración del consentimiento, antes bien que la coincidencia de la voluntad sicológica de oferente y aceptante ${ }^{44}$, que resulta del pensamiento de Pothier antes mencionado. En el Restatement of Contracts $2^{\text {nd }}$ (comentario al § 48) se critica "la obsoleta visión de que el contrato requeriría un "encuentro de mentes', porque "es inarmónica con la moderna doctrina de que una manifestación de asentimiento es efectiva sin atender al actual asentimiento mental". Además, el Código Civil costarricense (artículo 1014), el Código
41. Modificando el criterio del artículo 1322 del Código Civil de 1936.

42. También en esto, el artículo 681 del Código Civil paraguayo de 1987 se atiene al criterio antiguo: "La aceptación tardia [...] importará la propuesta de un nuevo contrato". El artículo 684 dispone que "si por alguna circunstancia la aceptación llegare tardíamente a conocimiento del oferente, éste lo comunicará sin dilación al aceptante, bajo pena de responder por los daños y perjuicios", pero ello no implica que el contrato pueda quedar formado; el articulo 5, inciso $3^{2}$, del Código Suizo de las Obligaciones da sentido a la disposición en estos términos: "si la aceptación expedida en tiempo llega tardiamente al oferente, y éste entiende no estar vinculado, debe informarlo inmediatamente al aceptante".

43. Declararon por unanimidad que "La idea de flexibilización del proceso de formación del contrato conduce a asignar al oferente $\mathrm{E}$ derecho de admitir las modificaciones no sustanciales a la oferta que introduzca el aceptante, asi como el de prevalerse de una aceptación tardía".

44. Conf. III Jornadas de Derecho Civil de La Pampa, Santa Rosa, 1991; V Jornadas Bonaerenses de Derecho Civil, Junín, 1992.

Revista da Faculdade de Direito da UFRGS, v. 18, 2000
Civil del Distrito Federal mexicano (artículo 1809) y el Código Civil peruano de 1984 (artículo 1383) excluyen la caducidad por muerte o incapacidad en casos de oferta simple; el Código Civil italiano de 1942, en los de oferta irrevocable (artículo 1329) y de oferta y aceptación por parte de un empresario (artículo 1330); en tanto el Código Civil austríaco descarta la retractación si "puede ser inferida una intención contraria del oferente" (artículo $866)^{45}$.

Con el sesgo de esta legislación moderna, el artículo 918 del Proyecto argentino de Código Civil de 1998 dispone: "La muerte, la incapacidad o la quiebra, del oferente o del aceptante, no perjudican respectivamente, la vigencia de la oferta $\mathrm{n}$ la eficacia de la aceptación recibida con posterioridad, salvo que lo contrario resulte de la ley, de la naturaleza de la obligación o de las circunstancias del caso".

El método del Proyecto argentino incluye partes generales, porque se ha considerado conveniente "sentar los principios de validez universal y, en su momento, delimitar los supuestos que se dejan de lado o se modifican" ${ }^{46}$ lo cual, por ejemplo, ha hecho posible "que las reglas de los contratos particulares sean exclusivamente las específicas a cada uno de ellos, evitándose reiteraciones inutiles y a veces contradictorias" ${ }^{47}$. De tal modo la fuerte influencia que han tenido los modernísimos antecedentes reseñados en la parte general de la teoría del contrato propaga su incidencia sobre la totalidad de las figuras contractuales particulares.
45. De los Fundamentos que acompañan al Proyecto de Código Civil argentino, № 163.

46. De la Nota de Elevación de fecha 18 de diciembre de 1998.

47. De los Fundamentos que acompañan al Proyecto de Código Civil argentino, № 182. 